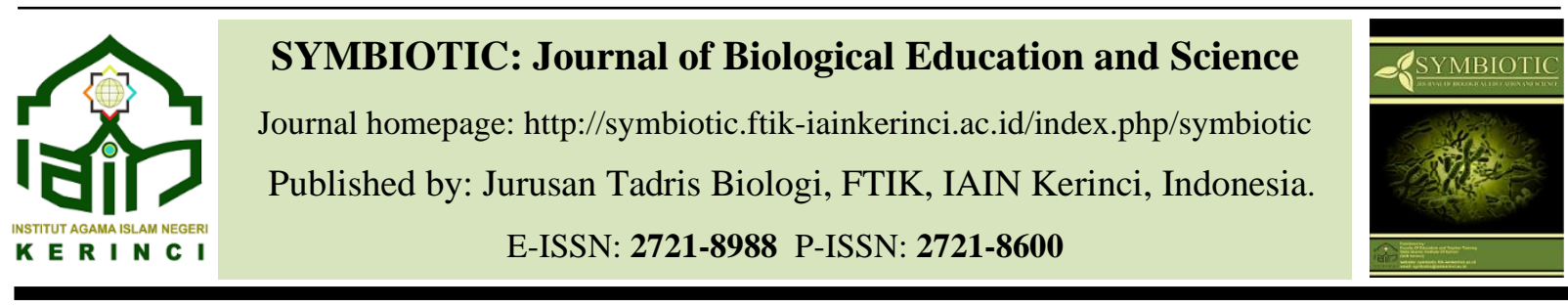

\title{
Pengetahuan Masyarakat Suku Tengger Terhadap Jenis Tumbuhan Liar Sebagai Bahan Bertahan Hidup Di Hutan Kawasan TNBTS, Kabupaten Malang Provinsi Jawa Timur
}

\author{
M. Eval Setiawan ${ }^{1}$, Suhadi' ${ }^{2}$, Sri Endah Indriwati ${ }^{3}$ \\ 1,2,3 Universitas Negeri Malang, Malang \\ e-mail korespondensi: evalsetiawan93@gmail.com
}

\begin{abstract}
Using the wild plant for consumptino is a knowledge passed down through generations that can be documented for the purposes of futher study. This study aim to document the kind of wlind plant for survival in TNBTS . the method used is descriptive analisis with data collection techniques throuhg indepth interviews and continued exploration of plants along the route to mount Semeru, the edge of the forest ant in the forest. Base on the result of in-depth interviews and exploration of found 9 species of plants that can be uses to survival material in TNBTS. Parts of the plants used is the leave. Plants in can be found alonge side the route of travel, the edge of the forets anf in the forest,
\end{abstract}

Keyword : Survival, Edible Wild Plant, TNBTS

\begin{abstract}
ABSTRAK
Penggunaan tumbuhan liar untuk konsumsi merupakan pengetahuan turun-temuran yang dapat didokumentasikan untuk keperluan kajian lebih lanjut. Penelitian ini bertujuan untuk mendokumentasikan jenis tumbuhan liar yang dapat digunakan untuk survival di kawasan TNBTS. Metode yang digunakan yaitu analisis deskriptif, dengan teknik pengumpulan data melalui wawancara secara mendalam dan dilanjutkan eksplorasi tumbuhan sepanjang rute perjalanan pendakian, tepi hutan dan dalam hutan. Berdasarkan hasil wawancara dan ekplorasi ditemukan 9 spesies tumbuhan yang dapat digunakan untuk bahan survival di kawasan TNBTS. Bagian tumbuhan yang digunakan yaitu daun. Tumbuhan ini dapat ditemukan dipinggir rute perjalanan, tepi hutan dan dalam hutan.
\end{abstract}

Kata Kunci: Bertahan Hidup, Tumbuhan Liar, TNBTS.

\section{PENDAHULUAN}

Masyarakat memanfaatkan lingkungan sekitar sebagai penunjang kehidupan. Lingkungan sekitar tempat tinggal akan menghasilkan berbagai macam bahan makanan yang dibutuhkan dalam kehidupan sehari-hari (Setiawan dkk, 2017). Salah satu pemanfaatan hutan yaitu penggunaan tumbuhan untuk konsumsi (Shtayeh dkk., 2008; Teketay dkk. 2010; Lukelat dkk. 2011; Neudeck dkk. 2012; Estrada-Castillo. 2014; Pieroni dkk, 2014). Tumbuhan tersebut dapat berupa tumbuhan yang dihalaman rumah ataupun tumbuhan liar (Cruz-Garcia \& Price, 2011; Luczaj dkk, 2013) di hutan.

Tumbuhan yang banyak digunakan oleh masyarakat tradisional yaitu tumbuhan yang hidup liar (Batoro dkk, 2010). Tumbuhan liar dapat diartikan sebagai tumbuhan yang tidak dirawat secara langsung (Beluhan \& Ranogajec, 2010; Turreire-Garcia dk, 2015). Tumbuhan liar ini dapat digunakan 
secara langsung sebagai bahan konsumsi. Penggunaan tumbuhan secara langsung dimaksudkan sebagai penggunaan tumbuhan tanpa menggunakan pengolahan secara khusus atau tumbuhan tersebut makan secara mentah (Setiawan, 2017).

Penggunaan tumbuhan untuk bertahan hidup ini dengan memilih bagian tumbuhan yang dapat digunakan di hutan . Bagian tumbuhan yang banyak dimanfaatkan untuk konsumsi yaitu daun, buah, batang dan akar atau umbi (Gerke, 2012; Estrada-Castillo, 2014; Pieroni dkk, 2014). Pada proses penggunaanya, pengguna harus memperhatikan bagian tumbuhan yang dapat untuk digunakan sebagai bahan konsumsi.

Keberadaan tumbuhan bertahan hidup di hutan ini akan membantu memberikan tambahan persediaan makanan untuk pencinta alam di hutan.

Suku tengger merupakan masyarakat yang telah tinggal di daerah sekitar Taman Nasional Bromo Tengger Semeru (TNBTS) (Suyitno, 2001). Masyarakat suku tengger telah memanfaatkan hutan sebagai penunjang kehidupan sehari-hari. Cara penggunaan tumbuhan liar yang digunakan oleh masyarakat didapatkan secara turun temurun (di Tazio dkk, 2012; Cruz dkk, 2013; Ju dkk, 2013; Ferry, 2019).

Pengetahuan masyarakat suku tengger tentang penggunaan tumbuhan sebagai bahan konsumsi merupakan salah satu aset budaya dan dapat dijadikan sebagai informasi dalam memanfaatkan tumbuhan di hutan. Informasi ini dijadikan bahan bacaan dalam menentukan jenis tumbuhan yang dapat dikonsumsi sebagai suplai makanan tambahan untuk bertahan hidup di hutan.

\section{METODE}

Metode yang digunakan deskriptif kualitatif. Dengan teknik pengumpulan data yaitu wawancara mendalam dan melakukan eksplorasi tumbuhan secara langsung di jalan menuju arah pendakian Gunung Semeru. Tumbuhan yang ditemukan di hutan kemudian diawetkan dan dibawa ke laboratorium Malangenis untuk diidentifikasi. Identifikasi tumbuhan ini dibantu oleh tim ahli dari Herbarium Malangensis dan dibantu beberapa sumber menggunakan buku Flora of Java jilid I, II dan III (Backer and Van Den Brink, 1963,1965 dan 1968), buku Flora Pergunungan Jawa (Van Stenis, 2010). Kegunaan tumbuhan yang telah ditemukan akan disesuaikan dengan buku Tumbuhan Berguna Indonesia jilid I, II, III, dan IV (Heyne, 1987), Edible Wild Plants (Oliver Perry Medsger, 196 2), dan buku The Complete Guide to Edible Wild Plants, Mushrooms, Fruits And Nuts: How To Find, Identify, And Cook Them (Katie Letcher Lyle, 2010).

\section{Populasi dan sampel}

Penelitian ini dilakukan di masyarakat sekitar Taman Nasional Bromo Tengger Semeru (TNBTS) yaitu masyarakat suku tengger yang tinggal di desa Ngadas kecamatan Poncokusumo Kabupaten Malang. Dengan melakukan wawancara kepada 15 informan kunci atau tokoh masyarakat adat di suku tengger. 


\section{HASIL DAN PEMBAHASAN}

Dari hasil wawancara bersama informan kunci maka diketui terdapat 9 jenis tumbuhan liar yang dapat digunakan untuk konsumsi di hutan. Tumbuhan ini berasal dari 7 suku dan 7 bangsa. Tumbuhan ini telah diidentifikasi di laboratorium Herbarium Malangensis. Hasil lengkap tumbuhan dapat dilihat pada tabel 1 .

Tabel 1. Jenis tumbuhan liar yang dapat dikonsumsi

\begin{tabular}{clccc}
\hline No & \multicolumn{1}{c}{ Jenis } & Nama Lokal & Suku & Bangsa \\
\hline 1 & Brassica rapa L. & Sawi liar & Brassicaceae & Brassicales \\
\hline 2 & Centela asiatica (L.) Urb & Pegagan & Apiaceae & Apiales \\
\hline 3 & $\begin{array}{c}\text { Crassocephalum crepidioides } \text { (Bentham) S. } \\
\text { Moore }\end{array}$ & Junggul & Asteraceae & \multirow{2}{*}{ Asterales } \\
\hline 4 & Diplazium esculentum (Retz.) Sw. & Pakis & Athriceae & Polypodiales \\
\hline 5 & Foeniculum vulgare Mill. & Adas & Apiaceae & Apiales \\
\hline 6 & Imperata cylindrical L. Reausch. & Ilalang & Poaceae & Poales \\
\hline 7 & Oxalis corniculata L. & Semanggen & Oxalidaceae & Geraniales \\
\hline 8 & Plantago major L & Daun sendok Plantaginaceae & Plantaginales \\
\hline 9 & Soncus oleraceus (L.) L. & Tempuyung & Asteraceae & Asterales \\
\hline
\end{tabular}

Dari hasil pada tabel 1 diketahui bahwa seluruh jenis tumbuhan yang temukan dapat dimanfaatkan bagian daunnya sebagai bahan survival di hutan. Berdasarkan informasi dari infoman kunci, tumbuhan tersebut dapat dimakan mentah (sebagai cemilan) atau direbus sebagai sayur. Spesies yang ditemukan tersebut dapat ditemukan sepanjang rute perjalanan pendakian, tepi hutan dan dalam hutan. Habitat tumbuhan berdasarkan tempat ditemukannya dapat dilihat pada gambar 1.

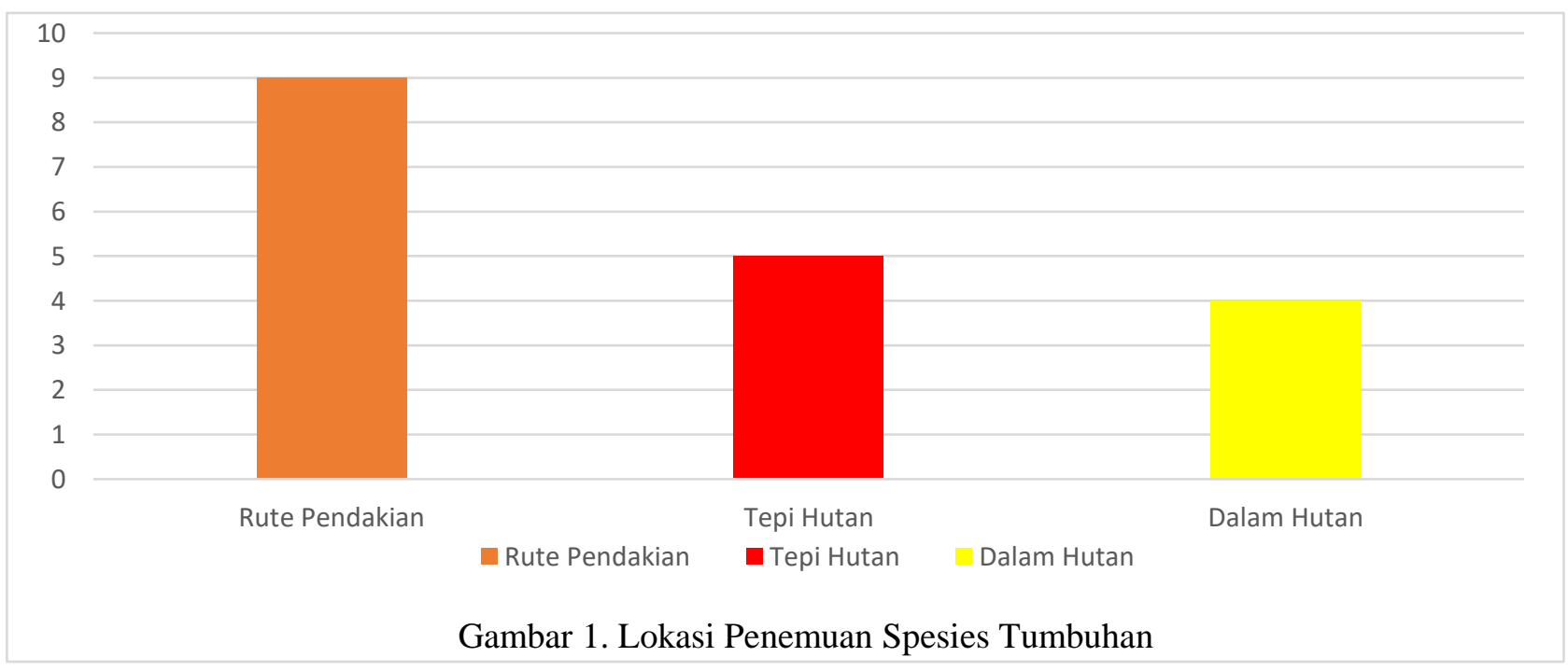

Gambar 1 menunjukkan bahwa keberadaan seluruh spesies tumbuhan ini tersedia di sekitar rute perjalanan menuju Gunung Semeru. Terdapat 5 spesies yang ditemukan di tepi hutan yaitu Centela asiatica (L.) Urb (Pegagan), Crassocephalum crepidioides (Bentham) S. Moore (Junggul), Diplazium esculentum (Retz.) Sw. (paku), Soncus oleraceus (L.) L. (Tempuyung) dan Foeniculum vulgare Mill. (adas). Kemudian terdapat 4 spesies ditemukan di dalam hutan, yaitu Centela asiatica 
(L.) Urb (Pegagan), Crassocephalum crepidioides (Bentham) S. Moore (Junggul), Diplazium esculentum (Retz.) Sw. (Pakis), dan Oxalis corniculata L. (Semanggen).

Dari gambar 1 dapat juga diketahui bahwa keberadaan lokasi menjadi pengaruh dalam menemukan spesies. Keberadaan lokasi dapat mempengaruhi ketinggiannya sehingga semua faktor lingkungan tumbuhnya tumbuhan akan berbeda. Perbedaan ini akan mempengaruhi pertumbuhan dan perkembangan tumbuhan. Faktor ini menjadi penentu keberadaan dari tumbuhan tersebut.

Bagian yang digunakan pada tumbuhan ini yaitu bagian daun seperti pada Centela asiatica (L.) Urb (Pegagan), Crassocephalum crepidioides (Bentham) S. Moore (Junggul), Oxalis corniculata L. (Semanggen). Soncus oleraceus (L.) L. (Tempuyung) dan Foeniculum vulgare Mill. (adas). Pemanfaatannya yaitu dimakan secara langsung atau dapat dimasak terlebih dahulu. Pengguna wajib mengenali secara baik jenis tumbuhan tersebut sebelum digunakan, agar tidak salah identifikasi.

Berdasarkan hasil survey bersama 15 orang warga Suku Tengger juga diketahui bahwa 100\% warga mengetahui ada tumbuhan yang digunakan untuk konsumsi secara langsung di hutan. Namun sebesar 93\% warga mengetahui seluruh jenis tumbuhan yang mampu dimanfaatkan untuk konsumsi. Selanjutnya sebesar $100 \%$ warga yang mengtahui jenis tumbuhan untuk konsumsi telah mengetahui jenis bagian yang digunakan dari tumbuhan tersebut. Pengetahuan masyarakat dapat dilihat dari tabel 2 berikut.

Tabel 2 Persentase Pengetahaun Masyarakat tentang Bagian Tumbuhan yang Digunakan Masyarakat

\begin{tabular}{|c|c|c|c|c|}
\hline \multirow[b]{2}{*}{ No } & \multirow[b]{2}{*}{ Responden } & \multicolumn{3}{|c|}{ Persentase } \\
\hline & & $\begin{array}{c}\text { Tumbuhan } \\
\text { Liar Konsumsi }\end{array}$ & $\begin{array}{c}\text { Pengetahuan Jenis } \\
\text { Tumbuhan }\end{array}$ & $\begin{array}{c}\text { Pengetahuan } \\
\text { Penggunaan }\end{array}$ \\
\hline 1 & $\mathrm{~A}$ & + & + & + \\
\hline 2 & $\mathrm{~B}$ & + & + & + \\
\hline 3 & $\mathrm{C}$ & + & + & + \\
\hline 4 & $\mathrm{D}$ & + & + & + \\
\hline 5 & $\mathrm{E}$ & + & + & + \\
\hline 6 & $\mathrm{~F}$ & + & + & + \\
\hline 7 & $\mathrm{G}$ & + & + & + \\
\hline 8 & $\mathrm{H}$ & + & + & + \\
\hline 9 & $\mathrm{I}$ & + & + & + \\
\hline 10 & $\mathrm{~J}$ & + & + & + \\
\hline 11 & $\mathrm{~K}$ & + & + & + \\
\hline 12 & $\mathrm{~L}$ & + & + & + \\
\hline 13 & $M$ & + & + & + \\
\hline 14 & $\mathrm{~N}$ & + & + & + \\
\hline 15 & $\mathrm{O}$ & + & - & - \\
\hline & rsentase & 100 & 93 & 93 \\
\hline
\end{tabular}

*tanda + berarti mengetahui dan tanda - berarti tidak mengetahui

Jenis tumbuhan yang diketahui oleh informan telah menunjukkan bagian yang digunakan untuk proses konsumsi. Informan memiliki pengetahuan yang baik dalam 
penggunaan bagian daun pada tumbuhan untuk proses konsumsi. Bagian tersebut dapat digunakan untuk lalapan, dibuat sayur ataupun ditumis dengan sayur lainnya.

Penelitian ini menunjukkan bahwa jenis tumbuhan yang ditemukan tersebut telah digunakan oleh masyarakat suku tengger sebagai lalapan atau dimasak sebagai sayur untuk keperluan sehari-hari. Namun penggunaan tumbuhan ini bukan menjadi makanan pokok, hanya sebagai pelengkap atau varian makanan yang mampu didapatkan dari alam sekitar. Masyarakat suku tengger mengakui bahwa tumbuhan liar ini sangat mudah ditemukan di sekitar tempat tinggal mereka.

\section{KESIMPULAN}

Berdasarkan hasil wawancara mendalam bersama informan kunci dan eksplorasi hutan di kawasan TNBTS ditemukan sebanyak 9 spesies tumbuhan liar yang dapat dikonsumsi untuk survival. Keseluruhan tumbuhan tersebut dapat manfaatkan pada bagian daun. Tumbuhan tersebut dapat digunakan secara langsung atau dimasak terlebih dahulu. Perlu dilakukan penelitian lanjutan dalam melihat jenis spesies lain pada lokasi yang berbeda sebagai upaya pengumpulan informasi tentang tumbuhan liar untuk konsumsi sebagai upaya bertahan hidup di hutan.

\section{UCAPAN TERIMA KASIH}

Penulis mengucapkan terima kasih kepada seluruh elemen yang terlibat di penelitian ini seperti kantor Taman Nasional Bromo Tengger Semeru (TNBTS) di kota Malang dan kantor wilayah Resort Pengelolaan Taman Nasional (RPTN) II 'Coban trisula' atas izin penelitian yang diberikan. Kemudian ucapan terima kasih atas kesediaan key informant informan kunci dalam membantu menemukan spesies di lokasi penelitian, dan kepada Tim LIPI Purwodadi, Jawa Timur atas kemudahan dan bantuan dalam mengidentifikasi spesies yang ditemukan di lapangan.

\section{DAFTAR RUJUKAN}

Ali-Shtayeh, M. S., Jamous, R. M., Al-Shafie', J. H., Elgharabah, W. A., Kherfan, F. A., Qarariah, K. H., ... Nasrallah, H. A. (2008). Traditional knowledge of wild edible plants used in Palestine (Northern West Bank): a comparative study. Journal of Ethnobiology and Ethnomedicine, 4(1): $1-13$.

Backer, CA. \& Bakhuizen van den Brink JR., RC. (1963). Flora of Java I. Netherland: WoltersNoorhoff NV-Groningen.

Backer, CA. \& Bakhuizen van den Brink JR., RC. (1965). Flora of Java II. Netherland: WoltersNoorhoff NV-Groningen.

Backer, CA. \& Bakhuizen van den Brink JR., RC. (1968). Flora of Java III. Netherland: WoltersNoorhoff NV-Groningen.

Batoro, J., Setiadi, D., Chikmawati, T., \& Purwanto, Y. (2010) Etnofarmakologi dan Pengetahuan Tumbuhan Obat Masyaraat Tengger di Bromo Tengger Semeru Jawa Timur. Jurnal Ilmu-Ilmu Hayati (Life Science) 22:43-50. 
Cruz, M. paloma, Peroni, N., \& Albuquerque, U. P. (2013). Knowledge, use and management of native wild edible plants from a seasonal dry forest (NE, Brazil). Journal of Ethnobiology and Ethnomedicine, 9(79): 1-10.

Cruz-Garcia, G. S., \& Price, L. L. (2011). Ethnobotanical investigation of "wild" food plants used by rice farmers in Kalasin, Northeast Thailand. Journal of Ethnobiology and Ethnomedicine, 7(1): $1-33$.

Di Tizio, A., Luczaj, L, J., Quave, C, L., Redzic, S., \& Pieroni, A. (2015). Traditional Food and Herbal Uses of Wild Plants in the Ancient South-Slavic Diaspora of Mundimitar/Montemitro (Southern Italy). Journal of Ethnobiology and Ethnomedicine, 8(21): 1-10.

Estrada-castillón, E., Garza-lópez, M., Villarreal-quintanilla, J. Á., Salinas-rodríguez, M. M., Sotomata, B. E., González-rodríguez, H., ... Cantú-ayala, C. 2014. Ethnobotany in Rayones , Nuevo León, México. Journal of Ethnobiology and Ethnomedicine, 10(62), 1-13.

Ferry, D. (2019). Local Wisdom Based Water Resources Conservation for Environmental Sustainability. Scientiae Educatia, 8(2), 220. doi:10.24235/sc.educatia.v8i2.2538

Gerke, R. 2010. Outdoor Survival guide. United Kingdom: human kinetics.

Ju, Y., Zhuo, J., Liu, B., \& Long, C. 2013. Eating From the Wild: Diversity of Wild Edible Plants Used by Tibetans in Shangri-la Region, Yunnan, China. Journal of Ethnobiology and Ethnomedicine, 9 (28): 1-22.

Lulekal, E, Z., Asfaw, E., Kelbessa \& P.V. Damme. (2011). Wild edible plants in Ethiopia: A review on their potential to combat food insecurity. Afrika Focus 24 (2):71-121.

Luzcas, L. (2008). Archival data on wild food plants used in Poland in 1948. . Journal of Ethnobiology and Ethnomedicine, 4 (4): 1-19.

Luczaj, L., Koehler, P., Piroznikow, E., Graniszewska, M., Pieroni, A., \& Gervasi, T. (2013). Wild edible plants of Belarus: from Rostafinski's questionnaire of 1883 to the present. Journal of Ethnobiology and Ethnomedicine, 9(21): 1-17.

Medsger, O, P. (1962). Edible Wild Plants. New York: The Macmillan Company.

Neudeck, L. L., Avelino, P., Bareetseng, B. N., Ngwenya, D., \& Teketay \& M.R. Motsholapheko. (2012). the Contribution of Edible Wild Plants to Food Security, Dietary Diversity and Income of Households In Shorobe Village, Northern Botswana. Ethnobotanical Research and Applications. 10: 449-462.

Pardo-de-Santayana, M., Tardio, J., Blanco, E., Carvalho, A. M., Lastra, J. J., San Miguel, E., \& Morales, R. (2007). Traditional knowledge of wild edible plants used in the northwest of the Iberian Peninsula (Spain and Portugal): a comparative study. Jurnal Ethnobiol Ethnomed, 3(27): $1-11$.

Pieroni, A., Cianfaglione, K., Nedelcheva, A., Hajdari, A., Mustafa, B., \& Quave, C. L. 2014. Resilience at the border: traditional botanical knowledge among Macedonians and Albanians living in Gollobordo , Eastern Albania. Journal of Ethnobiology and Ethnomedicine, 10(31), 131 
Teketay, D., F. Senbeta, M. Maclachlan, M. Bekele \& P. Barklund. (2010). Edible Wild Plants in Ethiopia. Ethiopia : Addis Ababa University Press, Addis Ababa.

Tilahun, T., \& Giday, M. (2010). Ethnobotanical study of wild edible plants of Kara and Kwego semipastoralist people in Lower Omo River Valley, Debub Omo Zone, SNNPR, Ethiopia. Journal of Ethnobiology and Ethnomedicine, 6(1): 23.

Tugume, P., Kakudidi, E. K., Buyinza, M., Namaalwa, J., Kamatenesi, M., Mucunguzi, P. \& Kalema, J. (2016). Ethnobotanical survey of medicinal plant species used by communities around Mabira Central Forest Reserve, Uganda. Journal of Ethnobiology and Ethnomedicine 12(5): 1-28.

Setiawan, M, E., Suhadi, Indrawati, S, I. 2017. Analisis pengetahuan mahasiswa pencinta alam tentang tumbuhan survival di hutan sebagai bahan pengembangan buku pegangan ilmiah populer. Jurnal Pendidikan Sains 4 (4): 144-151

Suyitno. 2001. Mengenal Upacara Tradisional Masayarakat Suku Tengger. Ttt: Satubuku.

Van Steenis, C. G. G. J. (2010). Flora Pergunungan Jawa. Bogor: LIPI. 